\title{
Synergistic Combination Effect of Green Organic Derivatives on the Corrosion Inhibition of Mild steel in Simulated Seawater
}

\author{
ROLAND TOLULOPE LOTO* and CLEOPHAS AKINTOYE LOTO
}

\author{
Department of Mechanical Engineering, Covenant University, Ota, Ogun State, Nigeria. \\ *Corresponding author E-mail: tolu.loto@gmail.com \\ http://dx.doi.org/10.13005/ojc/3404013
}

(Received: April 27, 2018; Accepted: June 22, 2018)

\begin{abstract}
Electrochemical studies of the synergistic combination of green organic derivatives, leucine and vanillin and the corrosion protection of mild steel in simulated seawater $(3.5 \mathrm{wt} . \% \mathrm{NaCl})$ was done using potentiodynamic polarization, open circuit potential and morphological analysis. Results showed the combined admixture performed effectively with highest inhibition value of $89 \%$ at $3 \%$ volumetric content of the admixture. The performance of the compound was observed to be proportional to concentration with mixed type inhibition characteristics. Significant anodic shift of corrosion potential occurred due to film formation compared to the control solution at relative thermodynamic stability. The inhibition mechanism of the admixture occurred through physisorption reaction from thermodynamic calculations according to Langmuir, Frumkin and Freudlich isotherms with correlation coefficient above 0.7 . Severe deterioration was observed on the morphology of mild steel without inhibitor compared to the steel from solution at highest inhibitor concentration.
\end{abstract}

Keywords: Corrosion, Steel, Inhibitor, $\mathrm{NaCl}$, Leucine, Vanillin.

\section{INTRODUCTION}

The corrosion process results in deterioration of the surface properties and metallic substrate of carbon steels. Corrosion initiates at flaws on the oxide film formed on the steel. The flaws are the products of discontinuities in the film, presence of impurities, inclusions and mechanical damage. In corrosive environments oxidation reactions occurs at the flaws resulting in the release of electron radicals, ferrous ions and eventual breakdown of the steel. The free electrons participate in the reduction reactions occurring at the metal/electrolyte interface where dissolved oxygen are present especially in aerated conditions, resulting in the formation of hydroxyl ions. Reaction between the hydroxyl and ferrous ions results in ferrous hydroxide, which transforms to hydrated oxide known as rust. The porosity of the hydrated oxide allows the continuity of the corrosion process leading to insidious degeneration and general surface deterioration of the steel ${ }^{1}$. The corrosion process is influenced by a number of factors such as types of corrosive species, presence of alloying elements, strength

This is an Open Access article licensed under a Creative Commons Attribution-Non Commercial-Share Alike 4.0 International License (https://creativecommons.org/licenses/by-nc-sa/4.0/), which permits unrestricted Non Commercial use, distribution and reproduction in any medium, provided the original work is properly cited. 
of the protective oxide film, temperature, amount of oxygen present, velocity of flow of the corrosive environment, extent of impurities etc. ${ }^{2}$ Despite the weak resistance of carbon steel to corrosion, it has extensive industrial application across most industries representing about $85 \%$ of the annual steel production worldwide due to their low cost, ready availability and good mechanical strength. Carbon steel corrosion is detrimental most especially in the presence of chlorides. Chlorides are majorly involved in corrosion reactions and kinetics of the corrosion process. Marine environments have abundance of chloride anions hence the serious debilitating effect of corrosion encountered metal alloys in such environments. The corrosion exists in different forms such as pitting, galvanic, cavitation and general corrosion. According to NACE the estimated cost of marine corrosion worldwide is about $\$ 80$ billion yearly ${ }^{3}$. Corrosion prevention by chemical compounds known as inhibitors has been proven to be one of the most feasible, reliable and cost effective methods ${ }^{4}$. Most corrosion inhibitors are organic derivatives consisting of heteroatoms and multiple bonds enabling strong intermolecular attraction and adsorption in the presence of corrosive anions ${ }^{5,6}$. Research on the use of corrosion inhibitors is geared toward the application of cost effective environmentally sustainable organic derivatives. Previous individual research on the corrosion inhibition effect of leucine and vanillin compounds have been done in acid solution with above average results $^{7-12}$. The purpose of this study is to assess the adsorption and corrosion inhibition performance of leucine and vanillin admixture on mild steel in 3.5\% $\mathrm{NaCl}$ solution.

\section{EXPERIMENTAL METHODS}

Mild steel (MS) obtained the open market and analysed at the Materials Characterization Laboratory, Department of Mechanical Engineering, Covenant University, Ota, Ogun State, Nigeria gave nominal (wt. \%) composition shown in Table 1. The mild steel is of cylindrical configuration with a diameter of $1.2 \mathrm{~cm}^{2}$. The steel was machined, sectioned and smoothened with silicon grinding papers $(80,320,600,800$ and 1000 grits), after with cleansed washing with deionized $\mathrm{H}_{2} \mathrm{O}$ and methyl-ketone. Leucine sourced from Sigma Aldrich, USA is a white powdered substance (molecular formular $\mathrm{C}_{6} \mathrm{H}_{13} \mathrm{NO}_{2}$ and molecular weight $131.17 \mathrm{~g} / \mathrm{mol}$ ). Its molecular structure is shown in Fig. 1(a). Vanillin is a phenolic aldehyde (molecular formular $\mathrm{C}_{8} \mathrm{H}_{8} \mathrm{O}_{3}$ and molecular weight 152.15 $\mathrm{g} / \mathrm{mol})$. Its molecular structure is shown in Fig. 1 (b). The admixed compound (LEV) was prepared in molar concentrations of $1.76 \times 10^{2}, 3.53 \times 10^{2}$, $5.29 \times 10^{2}, 7.06 \times 10^{2}, 8.82 \times 10^{2}, 1.06 \times 101 \mathrm{per}$ $200 \mathrm{~mL}$ of $3.5 \% \mathrm{NaCl}$ solution. Potentiodynamic polarization analysis was performed at $35^{\circ} \mathrm{C}$ with a triple electrode system (platinum counter electrode, $\mathrm{Ag} / \mathrm{AgCl}$ reference electrode and resin mounted MS with exposed surface area of $1.13 \mathrm{~cm}^{3}$ ) in $200 \mathrm{~mL}$ of the electrolyte within a transparent cell connected to Digi-Ivy 2311 potentiostat and interface with a computer. Graphs were produced at a scan rate of $0.0015 \mathrm{~V} / \mathrm{s}$ between potentials of $-1.25 \mathrm{~V}$ and +1.5 $\mathrm{V}$. Morphological representations of corroded and LEV inhibited MS morphology were studied after electrochemical analysis with Omax trinocular. Open circuit potential measurement (OCP) was done at $0.05 \mathrm{~V} / \mathrm{s}$ step potential for 3000 s to obtain information on thermodynamic stability and electrochemical equilibrium of MS without applied potentials.

Table 1: Composition (wt. \%) of Mild steel

\begin{tabular}{lccccccccc}
\hline Element Symbol & $\mathrm{C}$ & $\mathrm{Si}$ & $\mathrm{Mn}$ & $\mathrm{P}$ & $\mathrm{S}$ & $\mathrm{Cu}$ & $\mathrm{Ni}$ & $\mathrm{Al}$ & $\mathrm{Fe}$ \\
$\%$ Composition & 0.401 & 0.169 & 0.440 & 0.005 & 0.012 & 0.080 & 0.008 & 0.025 & 98.86 \\
\hline
\end{tabular}<smiles>CC(C)C[C@H](N)C(=O)O</smiles>

(a)<smiles>COc1cc(C=O)ccc1O</smiles>

(b)
Fig. 1. Molecular structure of (a) Leucine and (b) Vanillin

\section{RESULT AND DISCUSSION}

\section{Potentiodynamic polarization}

The potentiodynamic polarization plots indicating the anodic-cathodic behavior of MS in LEV $/ 3.5 \% \mathrm{NaCl}$ solution is shown in Fig. 2 . Table 2 depicts the results of inhibition efficiency (Y), corrosion rate $\left(C_{R}\right)$, corrosion current $\left(C_{1}\right)$, corrosion current density $\left(C_{I D}\right)$, corrosion potential $\left(C_{P}\right)$, 
polarization resistance $\left(R_{p}\right)$, anodic Tafel slope $\left(B_{a}\right)$ and cathodic Tafel slope $\left(B_{c}\right)$ from the polarization test. MS at $0 \%$ and $0.5 \% \mathrm{LEV}$ severely deteriorated in the presence of $\mathrm{Cl}^{-}$ions attaining corrosion rate values of $2 \mathrm{~mm} / \mathrm{y}$ and $1.99 \mathrm{~mm} / \mathrm{y}$. The corrosion reaction process takes place when MS loses electrons, releasing ferrous cations into the solution which transforms into ferric cations. The cathodic reaction in aerated condition occurs through oxygen reduction by gaining electron radicals. The corrosion reaction process causes the formation rust oxides on MS surface; however the porosity of the oxide formed allows $\mathrm{Cl}^{-}$ions to penetrate easily through the oxide layer. This allows the corrosion reaction mechanism responsible for anodic degradation to continue causing deeper attack on the steel substrate and releasing more $\mathrm{Fe}^{+}$ions into the electrolyte. LEV at $0.5 \%$ was unable to inhibit the corrosion of MS due to insufficient protonated molecules to oppose the deterioration effect of $\mathrm{Cl}^{-}$ions. As a result the change in corrosion rate and corrosion current density is marginal, though. The anodic tafel slope value decreased from $16.140 \mathrm{~V} / \mathrm{dec}$ to $13.630 \mathrm{~V} / \mathrm{dec}$ as a result of decrease in anodic current density resulting from metal dissolution reactions on the steel surface. The $C_{I D}$ values decreased with increment in LEV concentration and hence the inhibitor protection value (Table 2) is due to the adsorption reaction on MS surface. At $1 \%-2 \%$ LEV, the corrosion rate has decreased to values between $0.96 \mathrm{~mm} / \mathrm{y}$ and $0.75 \mathrm{~mm} / \mathrm{y}$ corresponding to inhibition efficiencies of $51.84 \%, 55.45 \%$ and $62.73 \%$ respectively due to the availability of sufficient LEV molecules to inhibition the electrochemical action of chlorides. It shows the inhibition performance of LEV is concentration dependent. While changes in the cathodic Tafel slope was marginal, a significant decrease in anodic Tafel slope was observed beyond $0.5 \%$ LEV due to decrease in anodic reactions on the steel, however changes in anodic Tafel slope vales from 1\% LEV to $2 \%$ LEV are quite negligible.

Observation of the polarization plot shows the cathodic branches of the plot with respect to LEV concentration are quite similar indicating the cathodic reaction mechanism involving oxygen reduction and production of hydroxyl ions is under activation control. The anodic branch of the polarization plot at $0 \% \mathrm{LEV}$ and $0.5 \% \mathrm{LEV}$ were linear due to oxidation reaction on MS surface causing the release of $\mathrm{Fe}^{2+}$ ions into the electrolyte as earlier mention, however beyond $0.5 \%$ LEV short passivation behavior was observed due to the inhibiting action of LEV compound. It shows the inhibition mechanism is through surface coverage whereby the reactive sites on the steel surface are enveloped by LEV molecules thereby suppressing the oxidation reactions. At $2.5 \%$ LEV and $2 \%$ LEV, the inhibition efficiency has attained values of $80.85 \%$ and $89 \%$ respectively signifying effective inhibition of MS corrosion. The maximum change in corrosion potential of MS between $0 \%$ LEV and $1 \%$ LEV in the reduction reaction direction is $81 \mathrm{mV}$ thus it is a mixed type inhibitor ${ }^{13}$.

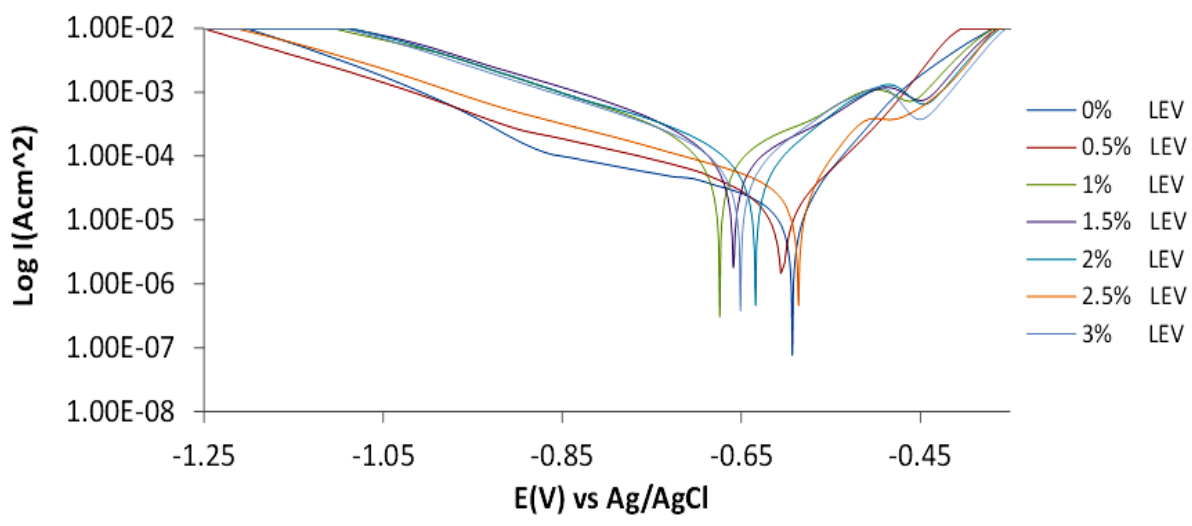

Fig. 2. MS corrosion polarization plots from $3.5 \% \mathrm{NaCl} / 0 \%$ - $2.5 \%$ LEV

\section{Mechanism of LEV inhibition}

LEV consisting of leucine and vanillin are compounds consisting of organic molecules which adsorbs on the metallic surface during corrosion inhibition reactions, as a result hinders metal oxidation through blockage of the cathodic and/ or anodic half-cell reactions. These compounds form precipitates with metal cations on the ionized 
metal surface ${ }^{14}$. Observation of the inhibition reaction mechanism in the presence of LEV shows passivation resulting from film formation (surface coverage) of protonated LEV molecules occurred on MS surface as evident on the anodic branch of the polarization plots. This is further confirmed from the increase in surface coverage with increase in LEV concentration, which shows the amount of LEV molecules present significantly influence the corrosion of $\mathrm{MS}^{15}$. Most organic compounds are electrons and when in the vicinity of electron acceptor metallic atoms donor-acceptor interchange occurs among the heteroatoms of LEV and the empty'd' orbitals of MS. This process does occur through chemisorption reaction mechanisms and or through electrostatic interaction between the molecular species.

Table 2: Results of potentiodynamic polarization test of MS corrosion in $3.5 \% \mathrm{NaCl} / 0 \%-2.5 \% \mathrm{LEV}$

\begin{tabular}{lcccccccccc}
\hline Sample & $\begin{array}{c}\text { LEV } \\
\text { Conc. (\%) }\end{array}$ & $\begin{array}{c}\text { LEV } \\
\text { Conc. (M) }\end{array}$ & $\begin{array}{c}M^{2} \mathrm{C}_{\mathrm{R}} \\
(\mathrm{mm} / \mathrm{y})\end{array}$ & $\begin{array}{c}\mathrm{LEV} \\
\mathrm{Y},(\%)\end{array}$ & $\mathrm{C}_{\mathrm{l}}(\mathrm{A})$ & $\begin{array}{c}\mathrm{C}_{\mathrm{ID}} \\
\left(\mathrm{A} / \mathrm{cm}^{2}\right)\end{array}$ & $\mathrm{C}_{\mathrm{p}}(\mathrm{V})$ & $\mathrm{R}_{\mathrm{p}}(\Omega)$ & $\begin{array}{c}\mathrm{B}_{\mathrm{c}} \\
(\mathrm{V} / \mathrm{dec})\end{array}$ & $\begin{array}{c}\mathrm{B}_{\mathrm{a}} \\
(\mathrm{V} / \mathrm{dec})\end{array}$ \\
\hline $\mathrm{A}$ & 0 & 0 & 2.00 & 0 & $1.95 \mathrm{E}-04$ & $1.73 \mathrm{E}-04$ & -0.593 & 116.00 & -4.167 & 16.140 \\
$\mathrm{~B}$ & 0.5 & $1.76 \mathrm{E}-02$ & 1.99 & 0.73 & $1.93 \mathrm{E}-04$ & $1.71 \mathrm{E}-04$ & -0.604 & 108.00 & -6.002 & 13.630 \\
$\mathrm{C}$ & 1 & $3.53 \mathrm{E}-02$ & 0.96 & 51.84 & $9.38 \mathrm{E}-05$ & $8.30 \mathrm{E}-05$ & -0.674 & 273.80 & -6.573 & 5.744 \\
$\mathrm{D}$ & 1.5 & $5.29 \mathrm{E}-02$ & 0.89 & 55.45 & $8.68 \mathrm{E}-05$ & $7.68 \mathrm{E}-05$ & -0.659 & 296.00 & -7.401 & 7.001 \\
$\mathrm{E}$ & 2 & $7.06 \mathrm{E}-02$ & 0.75 & 62.73 & $7.26 \mathrm{E}-05$ & $6.42 \mathrm{E}-05$ & -0.634 & 353.90 & -6.639 & 6.681 \\
$\mathrm{~F}$ & 2.5 & $8.82 \mathrm{E}-02$ & 0.38 & 80.85 & $3.73 \mathrm{E}-05$ & $3.30 \mathrm{E}-05$ & -0.586 & 688.90 & -4.579 & 6.306 \\
$\mathrm{G}$ & 3 & $1.06 \mathrm{E}-01$ & 0.22 & 89.00 & $2.14 \mathrm{E}-05$ & $1.90 \mathrm{E}-05$ & -0.651 & 759.70 & -6.560 & 6.010 \\
\hline
\end{tabular}

\section{Open circuit potential measurement}

The thermodynamic stability of MS in $3.5 \% \mathrm{NaCl} / 0 \%, 0.5 \%$ and $3 \% \mathrm{LEV}$ is shown in the variation of OCP versus exposure time (Fig. 3.). MS at $3.5 \% \mathrm{NaCl} / 0 \%$ LEV generally depicts the most electronegative results due to redox electrochemical processes on the steel surface. At $26.45 \mathrm{~s}$ its OCP value is most electronegative $(-0.680 \mathrm{~V})$ due to active corrosion of the steel. The OCP progress sharply at short time interval to $-0.503 \mathrm{~V}$ at $200 \mathrm{~s}$ due to short instantaneous passivation of the steel resulting from the formation of surface oxide, however the oxide formed are porous in nature, as a result the OCP immediately decreased to $-0.551 \mathrm{~V}$ at $500 \mathrm{~s}$ before remaining marginally stable till $750.01 \mathrm{~s}(-0.554 \mathrm{~V}$. Beyond this point the OCP values of MS at $3.5 \%$
$\mathrm{NaCl} / 0 \%$ LEV continue to decrease till $3200 \mathrm{~s}$. The presence of LEV at $0.5 \%$ concentration caused an instantaneous increase in OCP due to marginal passivation of MS $250 \mathrm{~s}$ at $-0.559 \mathrm{~V}$, beyond which the OCP value remained thermodynamically stable and at higher OCP values than MS at $0 \%$ LEV. At $3 \%$ LEV the OCP value of MS starting at -0.605 $\mathrm{V}(0 \mathrm{~s})$ increased to $-0.460 \mathrm{~V}$ at $300 \mathrm{~s}$ due to the corrosion inhibiting action of LEV. A progressive but stable marginal decrease later occurred till the end of the OCP test. It must be noted that MS at $3 \%$ is significantly more anodic than its counterparts due to interdiction of the oxidation-reduction reactions. The relatively positive values of MS at this concentration shows surface coverage by LEV molecules protected the steel

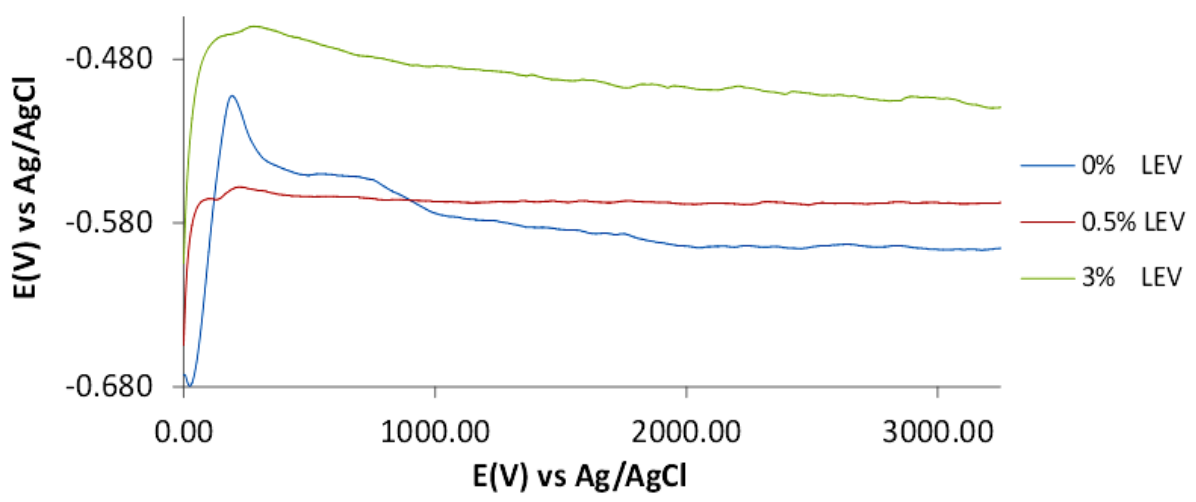

Fig. 3: Variation of MS OCP values versus exposure time in $3.5 \% \mathrm{NaCl} / \mathrm{LEV}$ compound 


\section{Adsorption isotherm studies}

Adsorption of inhibitor molecules onto metallic surfaces results from the electrostatic between them. Adsorption isotherms are graphical plots showing the amount of inhibitor molecules on metallic surfaces with respect to its concentration at fixed temperature. Langmuir, Frumkin and Freundlich isotherm models produced significantly high correlation coefficients amongst other isotherms evaluated to further understand the nature of LEV adsorption and corrosion inhibition of $\mathrm{MS}^{16}$. Langmuir isotherm states that in the presence of one adsorbate, metallic surfaces has fixed amount of adsorption sites with equal value of Gibbs free energy irrespective of the configuration of molecular arrangement and the effect of lateral synergy among the adsorbed inhibitor is negligible. Fig. 4 shows the graphical illustration of $\mathrm{C}_{\mathrm{LEV}} / \theta$ vs $\mathrm{C}_{\mathrm{LEV}}$ at correlation coefficient of 0.8024 with respect to Langmuir equation below.

$\theta=\left[\frac{K_{\mathrm{LEV}} C_{\mathrm{LEV}}}{1+K_{\mathrm{LEV}} C_{\mathrm{LEV}}}\right]$

$\theta$ is the sum of LEV a assimilated per unit gram on MS surface at constant temperature. $\mathrm{C}_{\mathrm{LEV}}$ is LEV concentration and $\mathrm{K}_{\mathrm{LEV}}$ is the equilibrium constant of adsorption. Frumkin isotherm states that surface coverage values is subject to the electrode potential resulting from changes in the energy of the double-layer capacitor due to the substitution of $\mathrm{H}_{2} \mathrm{O}$ molecules by organic molecules of organic compounds with having a lower dielectric constant. The metallic surfaces are non-homogeneous and the result of lateral synergy is important with respect to the equation below:

$$
(0 / 0-1)=K_{L E V} C e^{2 a 0}
$$

$\alpha$ is the lateral synergism parameter determined from the gradient of the graphical illustration of the Frumkin isotherm. $\mathrm{K}_{\mathrm{LEV}}$ is the adsorption-desorption constant. Graph of $\log [\theta /(1-\theta) c]$ against $\theta$ in Fig. 5(a) 0.9813 correlation coefficient. The Freundlich adsorption isotherm gives the experimental relationship between the amount of adsorbed inhibitor molecules by the unit mass of metal and concentration at a constant temperature according to the equation below. The Freundlich isotherm graph for LEV adhesion and assimilation in Fig. 5(b) gave 0.7570 correlation coefficient value. The equations below align with the Freundlich isotherm;

$$
\theta=\mathrm{K}_{\mathrm{LEV}} \mathrm{C}^{\mathrm{n}}
$$

$\log \theta=\mathrm{n} \log \mathrm{C}+\log \mathrm{K}_{\mathrm{LEV}}$

$\mathrm{n}$ is a constant subject to the properties of the inhibitor molecules involved in the adsorption reaction. $\mathrm{K}_{\mathrm{LEV}}$ is the adsorption-desorption equilibrium constant showing the adsorption strength.

\section{Thermodynamics of inhibitor adsorption}

Gibbs free energy data values determined from equation 5 below are depicted in Table 3.

$$
\Delta \mathrm{G}_{\mathrm{ads}}=-2.303 R \pi \log \left[55.5 \mathrm{~K}_{\mathrm{LEV}}\right]
$$

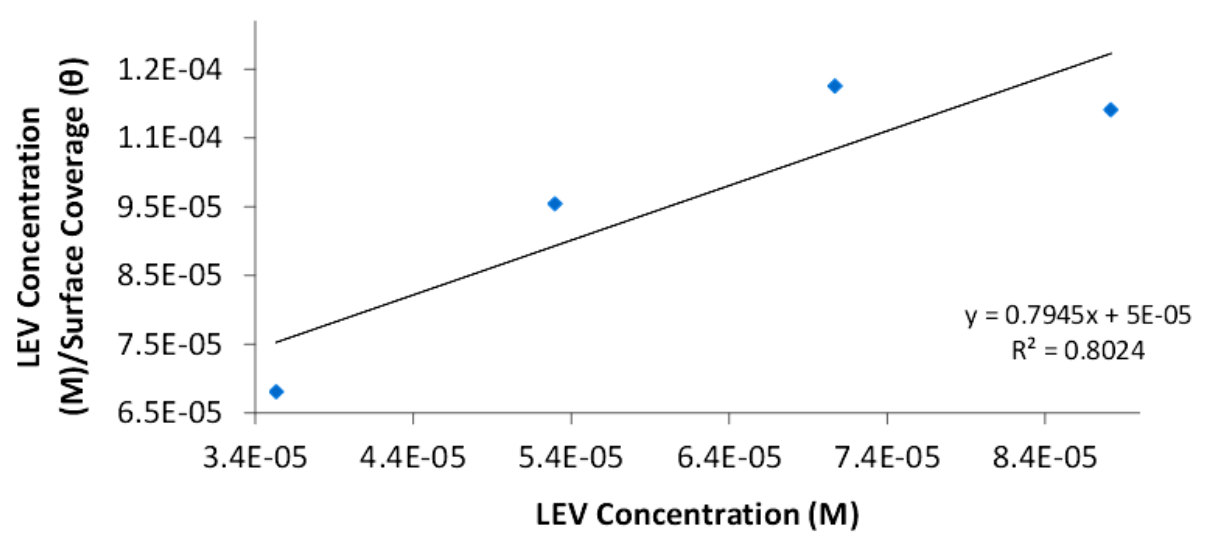

Fig. 4. Langmuir isotherm plot of $\mathrm{C}_{\mathrm{LEV}} / \theta$ versus LEV concentration 


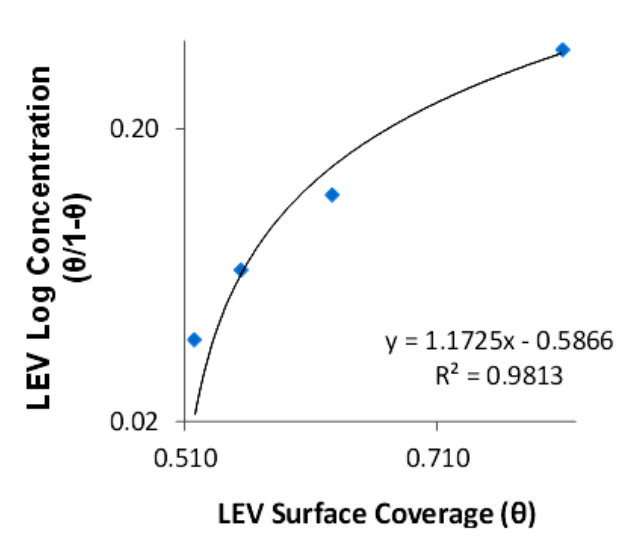

(a)

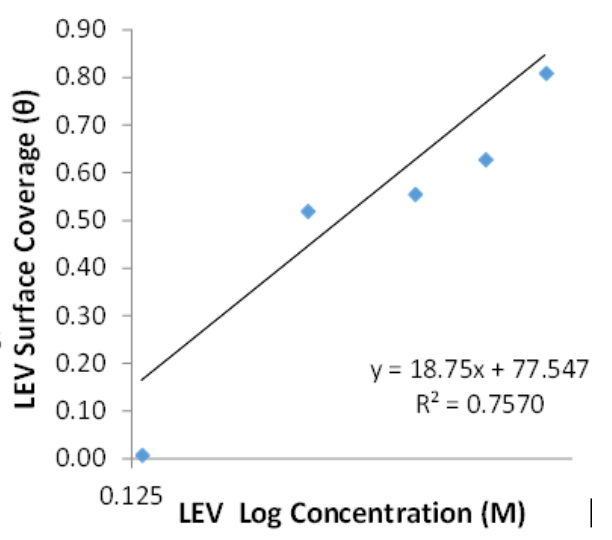

(b)

Fig. 5. (a) Graph of Frumkin isotherm, $\log [\theta /(1-\theta) c]$ versus $\theta$ and (b) Graph of Freundlich isotherm, log LEV concentration vs log surface coverage

55.5 is the molar concentration of $\mathrm{H}_{2} \mathrm{O}, \mathrm{R}$ is the ideal gas constant, $\mathrm{T}$ is the thermodynamic temperature and $\mathrm{K}_{\mathrm{LEV}}$ is the equilibrium constant of LEV adsorption on MS. The negative values of $\Delta \mathrm{G}_{\mathrm{ads}}$ results show the unconstrained nature and cohesion of adsorption. The highest $\Delta \mathrm{G}_{\text {ads }}$ value obtained is
$-20.70 \mathrm{KJmol}^{-1}$ while the lowest significant $\Delta \mathrm{G}_{\text {ads }}$ value obtained is $-18.42 \mathrm{KJmol}^{-1}$. The $\Delta \mathrm{G}_{\text {ads }}$ values shows the mechanism of adsorption is through physical attraction which shows that surface coverage of the inhibiting compound hinders the movement of the corrosive anions ${ }^{13,17}$.

Table 3: Gibbs free energy $\left(\Delta \mathbf{G}_{\text {ads }}\right)$, surface coverage $(\theta)$ and equilibrium constant of adsorption $\left(\mathrm{K}_{\mathrm{LEV}}\right)$ data for LEV adsorption on MS

\begin{tabular}{|c|c|c|c|c|}
\hline Sample & $\begin{array}{c}\text { LEV } \\
\text { Concentration (M) }\end{array}$ & $\begin{array}{c}\text { Surface } \\
\text { Coverage }(\theta)\end{array}$ & $\begin{array}{l}\text { Equilibrium Constant } \\
\text { of adsorption }\left(\mathrm{K}_{\mathrm{LEV}}\right)\end{array}$ & $\begin{array}{c}\text { Gibbs Free Energy, } \\
\qquad \Delta \mathrm{G}\left(\mathrm{Kjmol}^{-1}\right)\end{array}$ \\
\hline$A$ & 0 & 0 & 0 & 0 \\
\hline$B$ & 1.76E-02 & 0.007 & 0.42 & -7.79 \\
\hline C & 3.53E-02 & 0.518 & 30.49 & -18.42 \\
\hline $\mathrm{D}$ & 5.29E-02 & 0.555 & 23.53 & -17.78 \\
\hline$E$ & 7.06E-02 & 0.627 & 23.84 & -17.81 \\
\hline $\mathrm{F}$ & 8.82E-02 & 0.809 & 47.87 & -19.54 \\
\hline $\mathrm{G}$ & 1.06E-01 & 0.890 & 76.33 & -20.70 \\
\hline
\end{tabular}

\section{Morphological studies}

Morphological representations of MS before corrosion and after corrosion in $3.5 \% \mathrm{NaCl} / 0 \%$, $0.5 \%$ and $3 \%$ LEV solution from optical microscopy (mag. $x 40$ and $x 100$ ) are shown from Fig. 6(a) to 7(b). The morphology of MS in Fig. 6(b) significantly contrast the morphology in Fig 6(a) due to the debilitating action of $\mathrm{Cl}^{-}$ions as earlier discussed in the section under polarization studies. Numerous conjoined and enlarged corrosion pits in addition to general surface deterioration are clearly visible with iron oxides as corrosion product. Addition of LEV at $0.5 \%$ concentration [Fig. $7(\mathrm{a})$ ] did not offer any significant protection. General corrosion seems to have been inhibited however the corrosion pits on the surface appears larger. The MS morphology at 3\% LEV [Fig. 7(b)] shows a remarkable improvement in comparison to the earlier observed surfaces due to the inhibitive action of LEV, though mild deterioration is visible, it is superficial in nature as the integrity of the surface properties of MS is still intact. The superficial deterioration is probably due to initial attack by the $\mathrm{Cl}^{-}$ions before adsorption of the protonated inhibitor molecules which prevents 
further attack on the steel. However taking cue from adsorption isotherm studies it is also probable that lateral attraction between the inhibitor molecules

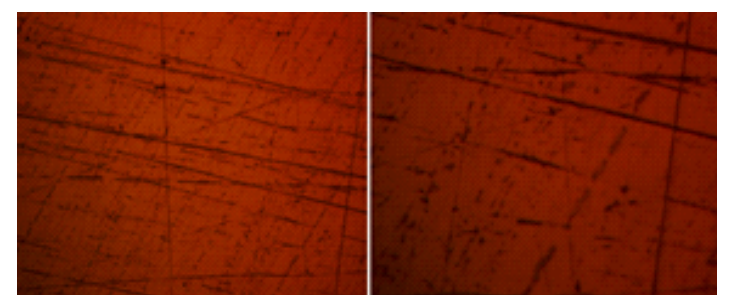

(a) results in an envelope covering (protective film) over the entire steel surface whereby the bulk of $\mathrm{Cl}^{-}$ions cannot diffuse through.

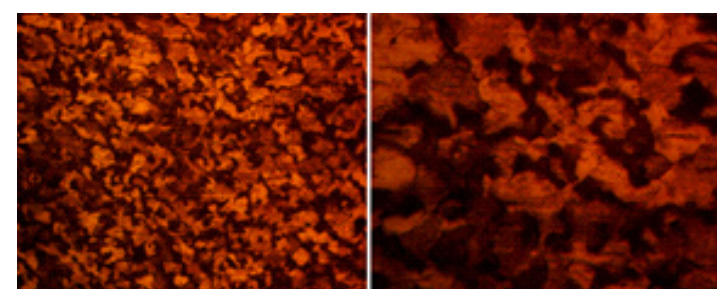

(b)

Fig. 6. Optical images of MS at mag. $x 40$ and $x 100$ (a) MS morphology before corrosion, (b) MS morphology after corrosion in $3.5 \% \mathrm{NaCl}$

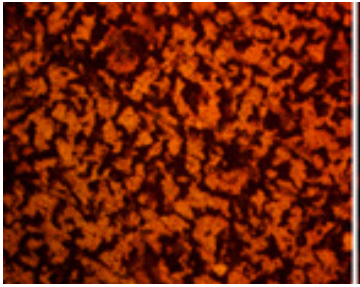

(a)

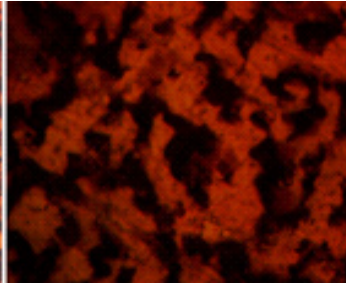

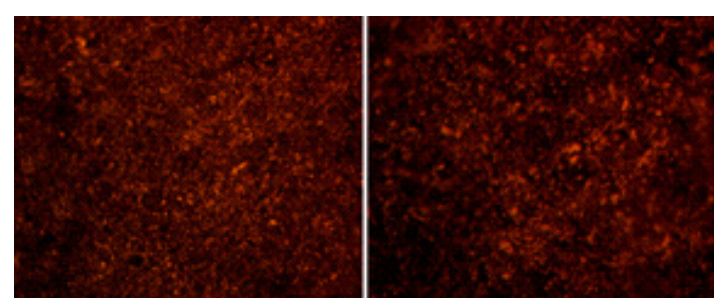

(b)

Fig. 7. Optical images of MS at mag. $x 40$ and $x 100$ (a) MS morphology after corrosion in $3.5 \% \mathrm{NaCl} / 0.5 \%$ LEV, (b) MS morphology after corrosion in $3.5 \% \mathrm{NaCl} / 3 \% \mathrm{LEV}$

\section{CONCLUSION}

The combined admixture of leucine and vanillin effectively inhibited the corrosion of mild steel in $3.5 \% \mathrm{NaCl}$ solution with maximum inhibition efficiency above $85 \%$. The inhibition mechanism was through surface coverage whereby inhibitor molecules formed a protective film over the steel surface. This caused a large anodic shift in corrosion potential from opencircuit potential analysis however, thermodynamic calculations show physisorption this project.

\section{REFERENCES}

1. Widder, S.H.; Baechler, M.C.; Impacts of water quality on residential water heating equipment, Pacific Northwest National Laboratory, Richland, Washington, 2013.

2. Zakowski, K.; Narozny, M.; Szocinski. M.; Darowicki, K. Influence of water salinity on corrosion risk the case of the southern baltic sea coast, Environmental Monitoring and Assessment., 2014, 186(8), 4871-4879. Maritime News, https://www.nace.org/ interaction between the protonated inhibitor molecules and the ionized steel surface occurred. Severe morphological deterioration of the steel with inhibitor compound significantly contrasts the morphology of the inhibited steel.

\section{ACKNOWLEDGEMENT}

The author acknowledges Covenant University Ota, Ogun State, Nigeria for the sponsorship and provision of research facilities for

resources/maritime-industry/.

4. Laamari, R.; Benzakour, J.; Berrekhis, F.; Abouelfida, A.; Derja, A.; Villemin, D. Arabian J. of Chem., 2011, 4, 271-277.

5. Ali, S.A.; Saeed, M.T.; Rahman, S.U. Corros. Sci., 2003, 45(2), 253-266.

6. Bereket, G.; Hur, E.; Ogretir, C. J. Mol. Struct. Theochem., 2002, 57(1-3), 79-88.

7. Ashassi-Sorkhabi, H.; Majidi, M.R.; Seyyedi, K. Appl. Surf. Sci., 2004, 225, 176-185.

8. Loto, R.T. J. Mater. Res. Technol. doi. 
org/10.1016/j.jmrt.2017.09.005.

9. Singh, P.; Bhrara, K.; Singh. G. Appl. Surf. Sci., 2008, 254, 5927-5935.

10. El-Etre, A.Y. Corros. Sci., 2001, 43(6), 1031-1039.

11. Samy, M.S.; Ismail, A.; Mohamed, M.E.; Soliman, E.A.; Moshira, Y.E. J. of Mol. Liq., 2015, 203, 20-28.

12. Loto, R.T. Cogent Eng., 2016, 3, 1242107. doi.org/10.1080/23311916.2016.1242107.

13. Loto, R.T.; Loto, C.A.; Popoola, A.P.I.;
Fedotova, T.I. J. Cent. South Univ., 2016, 23, 258-268.

14. Abdul Amir, H.K.; Abu Bakar, M.; Leiqaa, A.H.; Ahmed, A.A.; Ng, H.S.; Ahmed, Y.M. Materials MDPI., 2014, 7, 4335- 4348.

15. Mobin, M.; Parveen, M.; Alam Khan, M. Port. Electrochim. Acta., 2011, 29, 391-403.

16. Bulut, E.; Ozacar, M.; Sengil, I.A. Microporous Mesoporous Mater., 2008, 115(3), 234-246.

17. Loto, R.T.; Loto, C.A.; Joseph, O.O.; Olanrewaju, 